\title{
Porosity estimation of Phyllostachys edulis (Moso bamboo) by computed tomography and backscattered electron imaging
}

\author{
Puxi Huang' ${ }^{1}$ Wen-Shao Chang ${ }^{1}$. \\ Martin P. Ansell ${ }^{1}$. Chew Y. M. John' ${ }^{2}$. \\ Andy Shea ${ }^{1}$
}

Received: 6 October 2015/Published online: 23 September 2016

(C) The Author(s) 2016. This article is published with open access at Springerlink.com

\begin{abstract}
This study aims to investigate and quantify the porosity in the cross section of Phyllostachys edulis (Moso bamboo) culm wall. The porosity results are expected to be utilised in numerical study of heat and moisture transfer. Computed tomography (CT) and backscattered electron (BSE) imaging methods are utilised in this study because these two methods allow measurements of the anisotropic features of bamboo specimens. The results of these two methods can be represented as the function of the real dimension rather than the pore size distribution of the specimen. The specimens are obtained from eight different locations along the Moso bamboo culms. Both internodes and nodes specimens are measured in this study. The average porosity, standard deviation (SD) and coefficient of variation $(\mathrm{COV})$ are calculated for BSE and CT results. Pearson product-moment correlation coefficient (PPMCC) is also calculated in this study to analyse the correlation between the BSE results and CT results. Typical porosity results from 400 sampling points and 10 portions average porosity are analysed in this study. The CT scanning results show similar trend with BSE results. The correlation relationship between BSE and CT results approaches moderate correlation level to strong correlation level. The average porosity of internode specimens is from 43.9 to $58.8 \%$ by BSE measurement and from 44.9 to $63.4 \%$ by CT measurement. The average porosity of node specimens is from 37.4 to $56.6 \%$ by BSE measurement and from 32.1 to $62.2 \%$ by CT measurement.
\end{abstract}

Puxi Huang

P.huang@bath.ac.uk

1 Department Architecture and Civil Engineering, University of Bath, Bath, UK

2 Department of Chemical Engineering, University of Bath, Bath, UK 


\section{Introduction}

This study aims to quantify the porosity in the cross section of Phyllostachys edulis (Moso bamboo) culm wall. The results of this study will form the porosity database for conducting a heat and moisture transfer simulation. The porosity data could also be transferred to a fraction model to derive the basic equivalent thermal properties of Moso bamboo (e.g. equivalent thermal conductivity and heat capacitance).

Bamboo is a porous biological material. Light weight, competitive mechanical properties and fast reproductive speed make it distinctive to be utilised as an environmental building material (Isagi et al. 1997; Paudel and Lobovikov 2003; Van der Lugt et al. 2006). To evaluate the thermal and moisture performance at the material level, the knowledge of hydro-thermal behaviour of the material is indispensable. The porosity, density, thermal conductivity, specific heat capacity, vapour permeability and moisture capacity are the essential hydro-thermal properties required to conduct heat and moisture transfer simulations in the thermal performance of porous materials. Among these properties, the porosity could be regarded as the foundation parameter. Another name for porosity is void fraction which refers to the ratio of the void volume to the total volume. The phase of the void part of bamboo could be gas and liquid, while the phase of the skeletal part is solid (e.g. hemicellulose, cellulose and lignin). Remarkable differences in the physical properties exist in the different phases of bamboo. For example, the density of the air and water is 1.184 and $997 \mathrm{~kg} / \mathrm{m}^{3}$, respectively, at $25^{\circ} \mathrm{C}$. Previous studies found that the bulk density of Moso bamboo could reach up to $1412 \mathrm{~kg} / \mathrm{m}^{3}$ (Huang et al. 2015). Therefore, the skeletal density of the Moso bamboo is higher than this value. The fraction variation of the phases leads to the variations in other hydrothermal properties (Wu et al. 2013).

The porosity research on bamboo species is still under development compared with the similar research on wood. Mercury intrusion porosimetry (MIP), gas pycnometry (GP), microscopy image processing and computed tomography are some well-established technologies for porosity measurement in the wood research field. The application, strengths and limitations of these technologies are investigated as follows.

The porosity of five hardwood species and one softwood species has been investigated by MIP (Ding et al. 2008). The authors consider MIP as an effective method to measure the porosity of wood. Meanwhile, the limitation of MIP has also been stated as follows: High pressure may cause deformation of pores (Ding et al. 2008 cited in Stone 1964; Hill and Papadopoulos 2001). The theory of the MIP assumes that all pores are circular (Cook and Hover 1993). MIP may measure the pore entrance size rather than the actual pore size distribution (Roels et al. 2001; Giesche 2006). The anisotropic characteristics, for example density and porosity variation of the specimens in different locations, need to be carefully discussed (Almeida and Hernández 2006).

Gas pycnometry (GP) has been utilised in many papers on porosity research on wood. In Zauer's research (Zauer et al. 2013, 2014), the porosity and cell wall density of Norway spruce (Picea abies (L.) Karst.), sycamore maple (Acer 
pseudoplatanus L.) and European ash (Fraxinus excelsior L.) were analysed by the GP method. This method can achieve relatively high accuracy in the measurement of skeletal density and porosity. However, differences in preparation methods, measurement conditions and the displacement media can result in apparently different results (Stamm and Hansen 1937). The number of mesopores and macropores can be underestimated by some common absorption methods. In addition, the result of pore size distribution in GP corresponds to the pore size rather than the morphological porosity distribution.

Other porosity measurement methods are based on the stereological technologies which include three-dimensional reconstruction and image processing. The working principles, effective resolution and advantages of X-ray microtomography $(X-\mu C T)$, light microscopy (LM), scanning electron microscopy (SEM) and field-emission SEM (FE-SEM) have been illustrated in Chinga-Carrasco's study (Chinga-Carrasco 2002). The development of SEM and FE-SEM technologies allows the researchers to capture the image of their specimens at nanometre level. With the help of image recognition and processing software, the cell wall and lumen can be extracted for the purpose of calculating the porosity. Pan and Kudo (2011) have contributed a number of substantial insights to the segmentation of pores from the microscopic images of wood. A systematic algorithm has been utilised to recognise three different kinds of pore distributions in wood microscopic images (Pan and Kudo 2011). The two-dimensional cell porosity and thickness of the cell wall of Norway spruce have been investigated in a recent research (Derome et al. 2012). Although SEM images are often utilised for morphology studies of many wood species, the quantification of solid porosity from SEM images is rarely undertaken by researchers. Computed tomography (CT) scanning technology is a non-destructive method for obtaining the morphological information inside specimens (Iassonov et al. 2009). The X-ray computed tomography imaging has been utilised for the porosity measurement of the rocks (Taud et al. 2005). The application of CT scanning in the wood industry could be traced back to 1980s (Benson-Cooper 1982). The pore size and porosity of beech vessels have been investigated by X-ray tomographic microscopy (Hass et al. 2010). Although, a relatively high resolution has been achieved by the CT scanning method, the image recognition of porosity still remains at the level of vascular bundle vessels rather than the level of ground tissue pores. The main strength of using stereological technologies is that the actual morphological pore distribution of the specimen can be displayed directly. That means the porosity can be obtained as a certain orientation. The destruction of the specimen in the procedure of the porosity measurement is less than other aforementioned methods. A limitation of this technology is that the porosity measurement from SEM of the cross section is the two-dimensional porosity. In the image processing stage, it is difficult to provide a uniform standard for threshold transform. The porosity measurement depends on the image quality. Large amount of time is needed for transforming the visual information into numerical results.

The aforementioned techniques are summarised in Table 1.

Due to the importance and the influence of the porosity on the hydro-thermal properties of the Moso bamboo, this study aims to investigate and quantify the porosity in the cross section of the Phyllostachys edulis (Moso bamboo) culm wall. 
Table 1 Summary of current techniques on the porosity measurement

\begin{tabular}{|c|c|c|c|}
\hline Techniques & Strengths & Limitations & References \\
\hline MIP & Effective for woods & $\begin{array}{l}\text { Sample deformation } \\
\text { Assume all pores are circular } \\
\text { Porosity result is } \\
\text { corresponded to the pore } \\
\text { size of the sample }\end{array}$ & $\begin{array}{l}\text { Ding et al. (2008), Stone } \\
\text { (1964), } \\
\text { Hill and Papadopoulos } \\
\quad \text { (2001), } \\
\text { Cook and Hover (1993), } \\
\text { Roels et al. (2001), Giesche } \\
\text { (2006) } \\
\text { Almeida and Hernandez } \\
\text { (2006) }\end{array}$ \\
\hline GP & High accuracy & $\begin{array}{l}\text { Sample preparation and } \\
\text { displacement media need to } \\
\text { be treated carefully } \\
\text { Porosity result is } \\
\text { corresponded to the pore } \\
\text { size of the sample }\end{array}$ & $\begin{array}{l}\text { Zauer et al. (2013, 2014), } \\
\text { Stamm and Hansen (1937) }\end{array}$ \\
\hline LMISEM & $\begin{array}{l}\text { High resolution } \\
\text { Non-destructive } \\
\text { Porosity result is } \\
\text { corresponded to the real } \\
\text { position of the sample }\end{array}$ & $\begin{array}{l}\text { 2D measurement } \\
\text { Highly rely on the image } \\
\text { quality } \\
\text { No specific image processing } \\
\text { standard }\end{array}$ & $\begin{array}{l}\text { Chinga-Carrasco (2002), Pan } \\
\text { and Kudo (2011), Derome } \\
\text { et al. (2012) }\end{array}$ \\
\hline $\mathrm{CT} \backslash \mathrm{X}$-ray & $\begin{array}{l}\text { 3D measurement } \\
\text { Non-destructive } \\
\text { Porosity result is } \\
\text { corresponded to the real } \\
\text { position of the sample }\end{array}$ & $\begin{array}{l}\text { Low resolution } \\
\text { Slow in digitizing }\end{array}$ & $\begin{array}{l}\text { Iassonov et al. (2009), Taud } \\
\text { et al. (2005), Benson- } \\
\text { Cooper (1982) } \\
\text { Hass et al. (2010) }\end{array}$ \\
\hline
\end{tabular}

By considering the strengths and limitation of the existing porosity measurement technologies, both SEM and CT scanning method are utilised in this study. The main reason is that these two methods can determine the porosity distribution as the function of the orientation within Moso bamboo. The previous study has proved that the density and the fraction of vascular bundle tissue to ground tissue decrease from the external surface to the internal surface of the bamboo culm wall. This implies that the porosity has a similar trend with density (Huang et al. 2015).

\section{Materials and methods}

\section{Specimen preparation}

Eight Moso bamboo culms, cut from different height, were ordered from a bamboo supplier in the United Kingdom. The external diameter of these culms and recognition numbers are listed in Table 2. The specimens from each culm are divided into two major groups. The specimens of one group are cut from internodes part of the bamboo culm. The specimens of the other group are from nodes part (see Fig. 1). 
Table 2 Nomenclature of each specimen by external diameter sequence

\begin{tabular}{lllllllll}
\hline External diameter (mm) & $20-25$ & $30-35$ & $40-45$ & $50-55$ & $60-70$ & $70-80$ & $100-120$ & $120-150$ \\
\hline $\begin{array}{l}\text { Height of the cutting } \\
\text { position (m) }\end{array}$ & $>7$ & $6.5-7$ & $5.5-6.5$ & $4.5-5.5$ & $3.5-4.5$ & $2.5-3.5$ & $1.5-2.5$ & $0-1.5$ \\
$\begin{array}{l}\text { Internode } \\
\text { Node }\end{array}$ & $\mathrm{I} 1$ & $\mathrm{I} 2$ & $\mathrm{I} 3$ & $\mathrm{I} 4$ & $\mathrm{I} 5$ & $\mathrm{I} 6$ & $\mathrm{I} 7$ & $\mathrm{I}$ \\
\hline
\end{tabular}

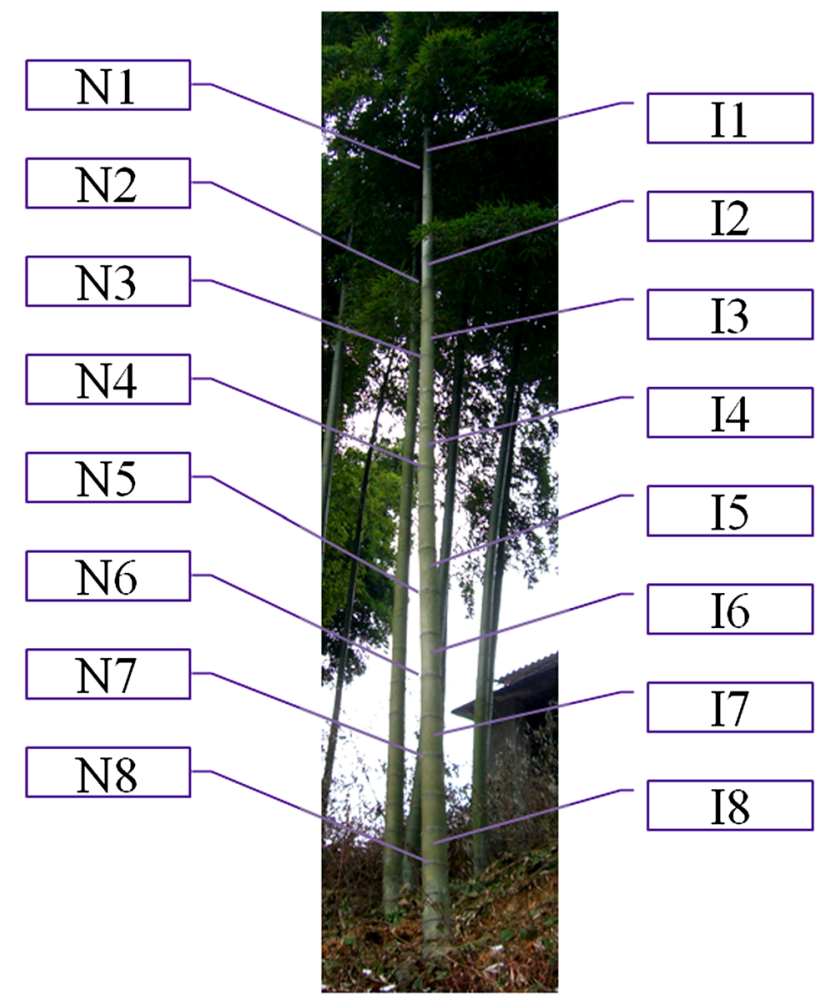

Fig. 1 Group number and cutting position of Moso bamboo

Bamboo specimens were oven-dried to eliminate the moisture at $103{ }^{\circ} \mathrm{C} \pm 2{ }^{\circ} \mathrm{C}$ for $24 \mathrm{~h}$. Then the specimens were stored in the desiccators with calcium chloride $\left(\mathrm{CaCl}_{2}\right)$ to avoid the moisture absorption. The specimens were cut into small pieces. The specimens were firstly utilised for CT scanning measurement. Same specimens were softened by water soaking at $70{ }^{\circ} \mathrm{C}$. The softened specimens need to be further cut by blades to form a flat surface for the SEM measurement. After cutting stage, the specimens were oven-dried again. Vacuum storing and gold sputter coating were conducted before the SEM measurement. The coating time was $3 \mathrm{~min}$. 


\section{CT scanning density measurement}

The CT scanning aims to obtain the bulk density of the specimens. Nikon XT H 225 CT scanner is utilised to capture the greyscale image of Moso bamboo specimens. The scanning parameters were fixed at a voltage of $90 \mathrm{kV}$ and current of $108 \mu \mathrm{A}$. Polypropylene (PP homopolymer) and acrylic were scanned simultaneously with bamboo specimens to obtain the linear relationship between the greyscale value and their actual bulk density. The bulk densities of these materials are known. The linear relationship could be expressed by Eq. 1.

$$
\rho_{\text {bulk }}=40.6 G s-70.4
$$

$\rho_{\text {bulk }}$ : Density $\left(\mathrm{kg} / \mathrm{m}^{3}\right)$.

Gs: Greyscale.

Previous study found that the linear relationship is only applicable to one single scanning. Any change on the settings will lead to a different linear relationship. Calibration needs to be conducted every time by scanning reference materials with known bulk density. The Avizo software is utilised to conduct the measurement of the greyscale of CT scanning image (Huang et al. 2015).

Five scan lines were placed in the cross section of each Moso bamboo specimen. The line thickness is $0.1 \mathrm{~mm}$. The distance between two adjacent lines is approximately $0.5 \mathrm{~mm}$. The CT scanning area with five lines, which is a representative area, is also the same as the area from backscattered electron (BSE) image (see Fig. 2). Every measurement line could obtain 500 greyscale values.

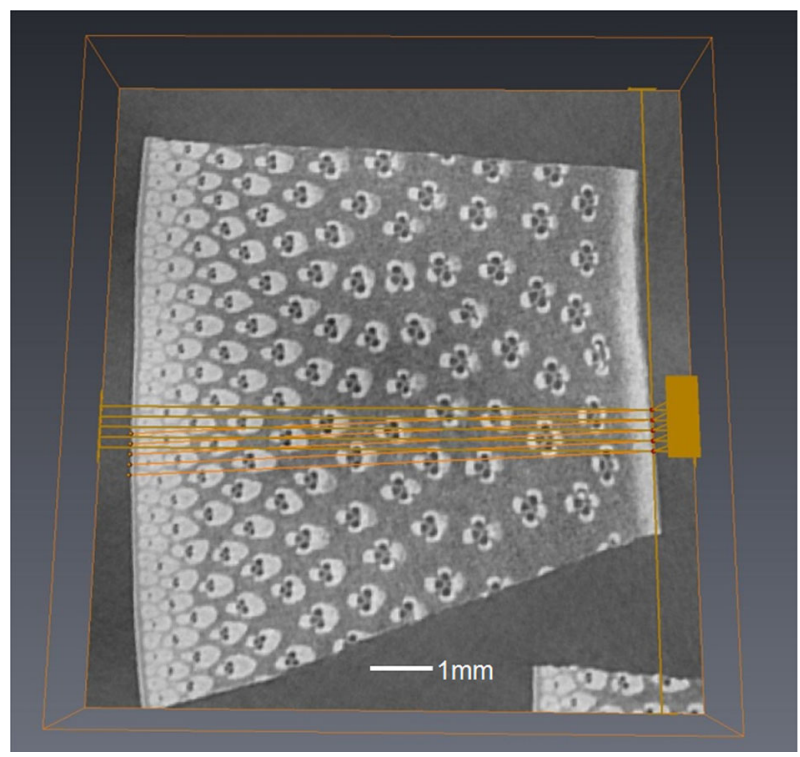

Fig. 2 CT scanning measurement area of a Moso bamboo specimen 
The average values of the five measurement lines are utilised as the bulk density to calculate the porosity by Eq. 2 .

$$
\rho_{\text {bulk }}=\rho_{s} \times(1-\phi)+\rho_{\text {air }} \phi
$$

$\rho_{\text {bulk: }}$ : Bulk density $\left(\mathrm{kg} / \mathrm{m}^{3}\right)$.

$\rho_{s}$ : Skeletal density $\left(\mathrm{kg} / \mathrm{m}^{3}\right)$.

$\phi$ : Porosity

$\rho_{\text {air }}$ : Air density $\left(1.184 \mathrm{~kg} / \mathrm{m}^{3}\right.$ at $\left.1 \mathrm{~atm}, 25^{\circ} \mathrm{C}\right)$.

If the bulk density and skeletal density are known, the porosity value could be obtained. The bulk density is obtained by CT scanning measurement. The cell wall density range of Moso bamboo is assumed in the range between 1425 and $1524 \mathrm{~kg} /$ $\mathrm{m}^{3}$. This range is obtained by the peak density value of the bamboo specimens in the CT scanning. The peak values generally appear at the epidermis side of the bamboo culm. The epidermis side is regarded as the side where the porosity tends to zero. The later SEM observation found that more pores, with the diameter less than $1 \mu \mathrm{m}$, appeared in the cell wall of internal side of the bamboo culm. Wood researchers often use $1500 \mathrm{~kg} / \mathrm{m}^{3}$ as the approximate cell wall density (Siau 1984). Three types of displacement media were utilised to measure the cell wall density of ten wood species. The measured density ranges from 1466 to $1548 \mathrm{~kg} / \mathrm{m}^{3}$ (Stamm 1929). In Kellogg and Wangaard's research (Kellogg and Wangaard 1969), the cell wall density for wood species ranges from 1497 to $1529 \mathrm{~kg} / \mathrm{m}^{3}$. It could be noticed that the cell wall density range of Moso bamboo is similar to the literature values of wood species.

\section{Backscattered electron (BSE) measurement}

Backscattered electron (BSE) images of the Moso bamboo specimens were captured by JEOL JSM-6480 scanning electron microscope (SEM) in the high vacuum mode. The beam accelerating voltage of the BSE is $15 \mathrm{kV}$ in this study. The magnification of the BSE is $60 \mathrm{X}$. The working distance and probe diameter are approximately 22 and $60 \mathrm{~nm}$, respectively. The BSE signal is from the elastically scattered electron which is deflected back from the specimen. The higher atomic mass elements have higher capability to backscatter the incident beam of electrons than the lower atomic mass elements. The result of this fact is that heavier elements contribute brighter pixels than lighter elements to the images (Solomonov et al. 2014). High-contrast BSE images are more helpful for distinguishing the air phase and bamboo cell wall phase. Figure 3 clearly shows the difference between the secondary electron (SE) image and BSE image.

The area of each pixel is $1 \mu \mathrm{m}^{2}$. The captured BSE images were merged by Adobe Photoshop software. Then, the merged images were processed by image $\mathbf{J}$ software. By adjusting the threshold, the BSE images were transferred into binary images. Binary image can be saved as a result file in matrix form. The greyscale 

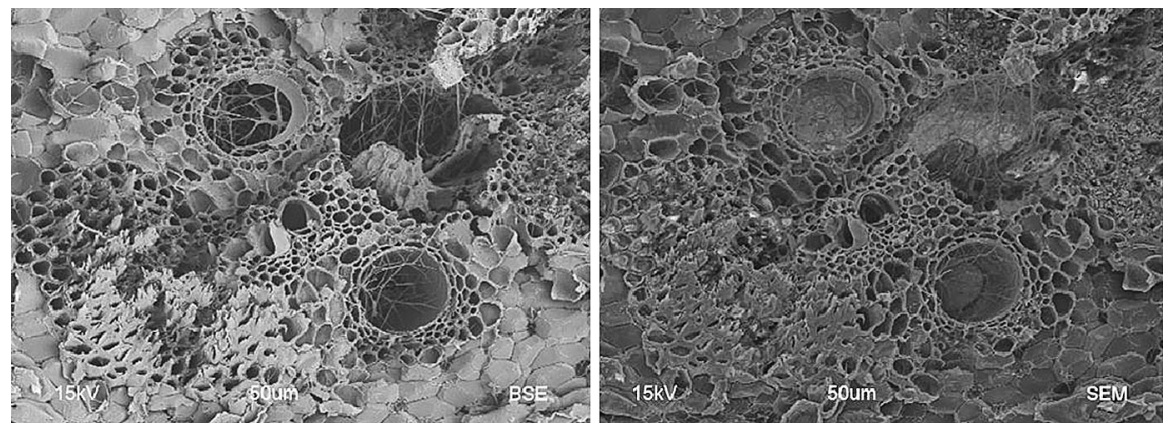

Fig. 3 Comparison between the secondary electron (SE) image and BSE image

value of white pixels is 0 which represented the bamboo cell wall phase, while the greyscale value of black pixels is 255 which represented the pore (air) phase. By calculating the average fraction between the 0 and 255 of every column of the matrix, the average porosity of bamboo specimens could be acquired. Figure 4 illustrates the procedure of BSE image processing.

\section{Results and discussions}

\section{Macro data statistics of BSE and CT scanning}

Macro data statistics of BSE and CT scanning aims to provide the average porosity, standard deviation (SD) and coefficient of variation (COV) of each group. Pearson product-moment correlation coefficient (PPMCC) was calculated to measure the linear correlation between the BSE results and CT scanning results (Table 3). Both BSE and CT scanning methods could discrete at least 400 sampling points. The number of sampling points depends on the thickness of bamboo culm wall. The PPMCC values were calculated by Eq. 3 (Dancey and Reidy 2004):

$$
r_{x y}=\frac{n \sum x y-\sum x \sum y}{\sqrt{n \sum x^{2}-\left(\sum x\right)^{2}} \sqrt{n \sum y^{2}-\left(\sum y\right)^{2}}}
$$

$r_{x y}$ : Pearson product-moment correlation coefficient (PPMCC).

$x, y$ : Two groups of data.

There are maximum and minimum CT scanning results in Table 3; their variation trend is exactly the same. Therefore, the PPMCC values between BSE results and maximum CT scanning results are equal to the PPMCC values between BSE results and minimum CT scanning results.

In internode specimens, the average porosity is from 43.9 to $58.8 \%$ by BSE measurement. The average porosity from CT scanning measurement is 44.9-60.9\% and $48.5-63.4 \%$ by minimum skeletal density calculation and maximum skeletal density calculation, respectively. The SD value is from 13.1 to $21.6 \%$ by using BSE measurement. The SD from CT scanning measurement is $15.3-23.6 \%$ and 

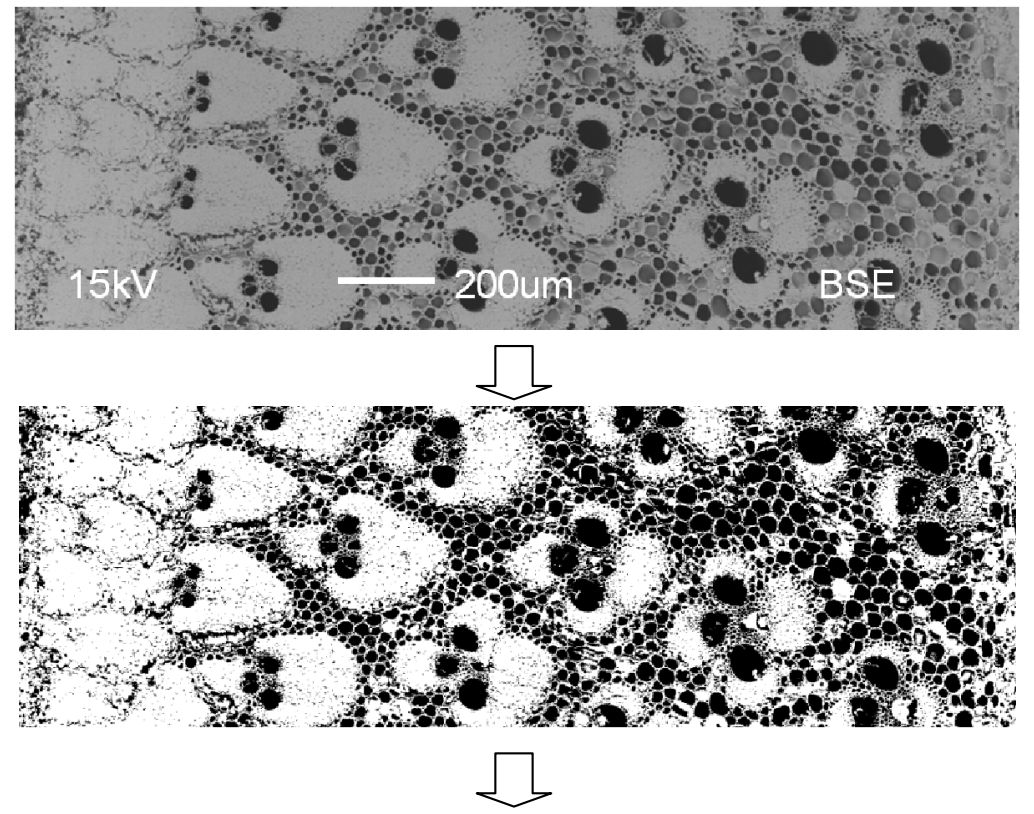

\begin{tabular}{|l|l|l|l|l|l|l|}
\hline$\cdots$ & $\cdots$ & $\cdots$ & $\cdots$ & $\cdots$ & $\cdots$ & $\cdots$ \\
\hline$\cdots$ & 255 & 255 & 255 & 255 & 255 & $\cdots$ \\
\hline$\cdots$ & 255 & 0 & 255 & 255 & 255 & $\cdots$ \\
\hline$\cdots$ & 0 & 0 & 0 & 255 & 255 & $\cdots$ \\
\hline$\cdots$ & 255 & 255 & 255 & 255 & 255 & $\cdots$ \\
\hline$\cdots$ & 255 & 255 & 255 & 255 & 255 & $\cdots$ \\
\hline$\cdots$ & 255 & 0 & 0 & 0 & 0 & $\cdots$ \\
\hline$\cdots$ & 255 & 0 & 0 & 0 & 255 & $\cdots$ \\
\hline$\cdots$ & 255 & 255 & 255 & 255 & 255 & $\cdots$ \\
\hline$\cdots$ & $\cdots$ & $\cdots$ & $\cdots$ & $\cdots$ & $\cdots$ & $\cdots$ \\
\hline
\end{tabular}
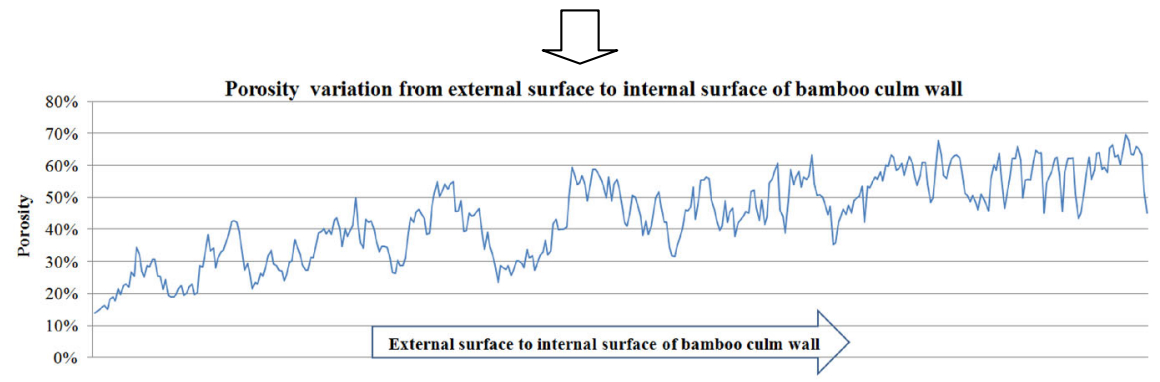

Fig. 4 Transfer procedure from BSE image to porosity values 
Table 3 Macro data statistics of BSE and CT scanning

\begin{tabular}{|c|c|c|c|c|c|c|c|c|c|c|}
\hline \multirow[t]{2}{*}{ No } & \multicolumn{3}{|c|}{ Average porosity (\%) } & \multicolumn{3}{|c|}{$\mathrm{SD}(\%)$} & \multicolumn{3}{|c|}{$\operatorname{COV}(\%)$} & \multirow{2}{*}{$\begin{array}{l}\text { PPMCC }^{\mathrm{a}}(\%) \\
{\mathrm{BSE} / \mathrm{CT}^{\mathrm{b}}}^{\mathrm{b}}\end{array}$} \\
\hline & BSE & $\mathrm{CT}_{\min }$ & $\mathrm{CT}_{\max }$ & BSE & $\mathrm{CT}_{\min }$ & $\mathrm{CT}_{\max }$ & BSE & $\mathrm{CT}_{\min }$ & $\mathrm{CT}_{\max }$ & \\
\hline \multicolumn{11}{|c|}{ Internode } \\
\hline I 1 & 43.9 & 44.9 & 48.5 & 13.1 & 15.3 & 14.4 & 29.8 & 34.2 & 29.6 & 78.8 \\
\hline I 2 & 58.8 & 60.9 & 63.4 & 21.6 & 23.6 & 21.5 & 49.3 & 52.5 & 34.0 & 70.3 \\
\hline I 3 & 52.4 & 54.4 & 57.4 & 18.2 & 18.6 & 17.0 & 41.5 & 41.5 & 29.7 & 80.8 \\
\hline I 4 & 47.6 & 49.9 & 53.2 & 17.5 & 16.0 & 14.7 & 39.9 & 35.6 & 27.7 & 68.0 \\
\hline I 5 & 51.9 & 53.6 & 56.6 & 18.5 & 19.7 & 18.1 & 42.3 & 43.8 & 31.9 & 71.1 \\
\hline I 6 & 57.5 & 56.6 & 59.4 & 21.4 & 20.7 & 18.9 & 48.8 & 46.1 & 31.8 & 76.8 \\
\hline I 7 & 53.6 & 53.0 & 56.1 & 16.5 & 15.7 & 14.3 & 37.7 & 35.0 & 25.5 & 72.2 \\
\hline I 8 & 49.8 & 50.9 & 54.1 & 14.7 & 16.1 & 14.9 & 33.4 & 35.9 & 27.5 & 75.9 \\
\hline \multicolumn{11}{|l|}{ Node } \\
\hline N 1 & 37.4 & 32.1 & 36.5 & 13.8 & 18.4 & 17.7 & 31.5 & 40.9 & 48.5 & 57.7 \\
\hline $\mathrm{N} 2$ & 41.0 & 42.8 & 46.5 & 14.2 & 19.5 & 18.4 & 32.3 & 43.5 & 39.5 & 65.5 \\
\hline N 3 & 56.6 & 59.6 & 62.2 & 23.3 & 23.7 & 21.7 & 53.1 & 52.8 & 34.8 & 70.7 \\
\hline $\mathrm{N} 4$ & 46.7 & 51.9 & 55.1 & 20.0 & 20.0 & 18.4 & 45.6 & 44.5 & 33.5 & 75.1 \\
\hline N 5 & 43.0 & 46.4 & 49.9 & 21.5 & 18.1 & 16.9 & 48.9 & 40.3 & 33.8 & 68.1 \\
\hline N 6 & 45.5 & 47.5 & 50.9 & 16.2 & 17.2 & 15.9 & 37.0 & 38.2 & 31.3 & 54.3 \\
\hline N 7 & 48.0 & 49.1 & 52.4 & 8.6 & 14.1 & 12.9 & 19.5 & 31.3 & 24.6 & 47.2 \\
\hline N 8 & 47.1 & 49.7 & 53.0 & 16.3 & 15.8 & 14.5 & 37.3 & 35.1 & 27.4 & 67.3 \\
\hline
\end{tabular}

a PPMCC values were calculated to measure the linear correlation between BSE results and CT scanning results

b PPMCC value between $\mathrm{BSE} / \mathrm{CT}_{\min }$ and $\mathrm{BSE} / \mathrm{CT}_{\max }$ is same because they use same bulk density value in Eq. 2

$14.3-21.5 \%$ by minimum skeletal density calculation and maximum skeletal density calculation, respectively. The COV value is from 29.8 to $49.3 \%$ by using BSE measurement. The COV from CT scanning measurement is $34.2-52.5 \%$ and $25.5-34.0 \%$ by minimum skeletal density calculation and maximum skeletal density calculation, respectively. The PPMCC between the BSE results and CT scanning results ranges from 68.0 to $80.8 \%$.

In node specimens, the average porosity is from 37.4 to $56.6 \%$ by BSE measurement. The average porosity from CT scanning measurement is $32.1-59.6 \%$ and $36.5-62.2 \%$ by minimum skeletal density calculation and maximum skeletal density calculation, respectively. The SD value is from 8.6 to $23.3 \%$ by BSE measurement. The SD from CT scanning measurement is $14.1-23.7 \%$ and $12.9-21.7 \%$ by minimum skeletal density calculation and maximum skeletal density calculation, respectively. The COV value is from 19.5 to $53.1 \%$ by BSE measurement. The COV from CT scanning measurement is $31.3-52.8 \%$ and $24.6-48.5 \%$ by minimum skeletal density calculation and maximum skeletal density calculation, respectively. The PPMCC between the BSE results and CT scanning results ranges from 47.2 to $75.1 \%$. 
The PPMCC results indicated that the correlation coefficient is at the moderate correlation level to the strong correlation level (Dancey and Reidy 2004). The PPMCC of internode specimens is higher than the node specimens. Therefore, porosity variation of the cross section (BSE results) could influence the total porosity variation (CT scanning results) of Moso bamboo specimens. The strength of the CT scanning is that porosity in the cell wall phase of the bamboo specimens can be obtained three dimensional, while BSE results are two dimensional.

\section{Typical porosity results of a specimen from CT scanning and BSE}

The typical porosity results aim to present the non-homogeneity on the pore distribution of the Moso bamboo. Both BSE and CT scanning methods could discrete at least 400 sample points. Figure 5 illustrates a typical porosity result of the Moso bamboo specimens. Results of I1 are from both CT scanning method and BSE image processing method.

The porosity was measured from the external surface to the internal surface of the cross section of the bamboo culm wall. The porosity values increased with remarkable fluctuations in this direction. The result indicated that the results from BSE image demonstrated similar trend to the results from CT scanning images. However, a number of different values appeared between two methods. The reason may include two aspects. One is that BSE method cannot detect the porosity of cell wall phase, but CT scanning measurement can be conducted in the threedimensional space. The other is that threshold image processing may cause some errors from the light and dark points of the BSE images.

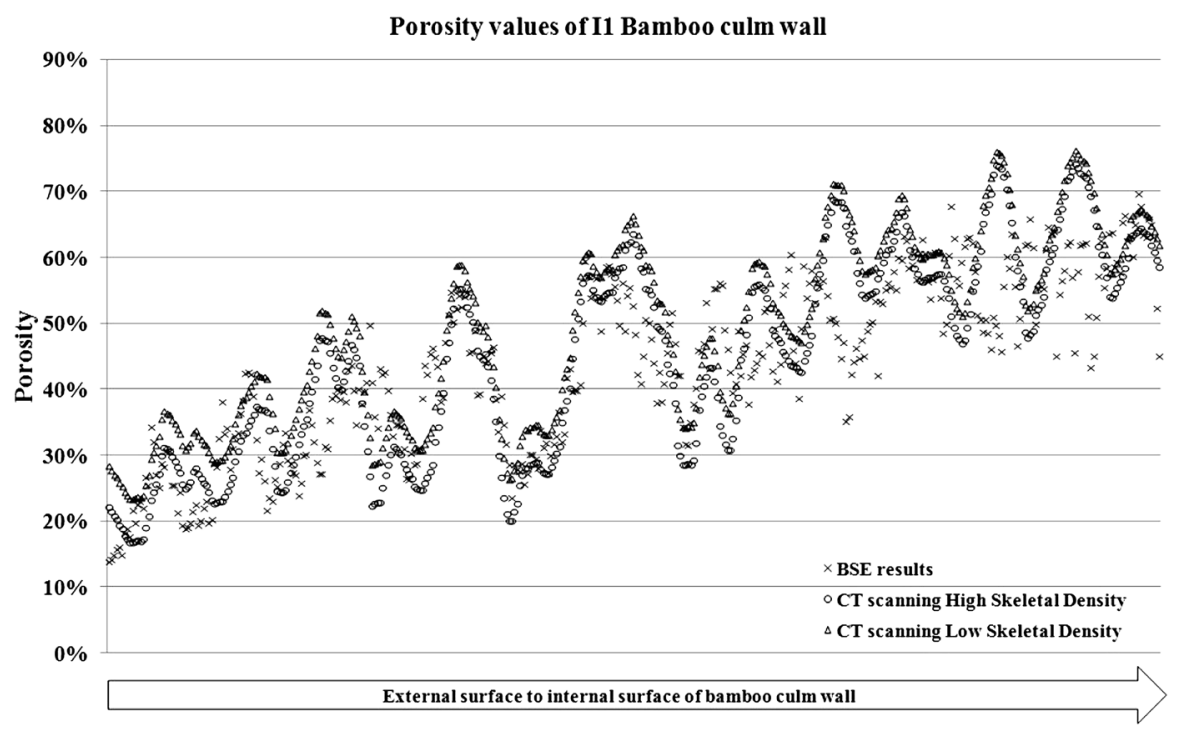

Fig. 5 Typical porosity results of a specimen from CT scanning and BSE 


\section{Average BSE and CT results}

Both macro data statistics and the typical results in Fig. 4 indicated that the porosity data show remarkable fluctuation and high variation from external side to internal side of bamboo culm wall. If all 400 data points and all groups are included in one diagram, the trend will be relatively difficult to make visible. Furthermore, huge data in the numerical simulation of the heat and moisture transfer will lead to longer computing time. In addition, the length of several small specimens is $<4 \mathrm{~mm}$. It is not worth to divide $4 \mathrm{~mm}$ into 400 times by the manufacturing machines in the wood industry.

Therefore, average statistics were made with the consideration of the ease of data comparison, the efficiency of numerical simulation and the manufacturing cost efficiency of the wood work machines. In detail, 400 data points of each specimen are divided into 10 equal portions from the external side to the internal side of the bamboo culm wall. Every portion, namely 40 data points, could generate an average value. For example, the number first value is the average of the first 40 samples points from external side of the bamboo culm. The number 8 is the average of the last 40 sample points from external side of the bamboo culm.

Figures 6 and 7 illustrate the porosity results of internode and node specimens from BSE and CT results. BSE results are displayed on the left side of the figure. The CT results are displayed on the right side of the figure. The data of Fig. 6 are from internode specimens, while the data of Fig. 7 are from nodes specimens. The
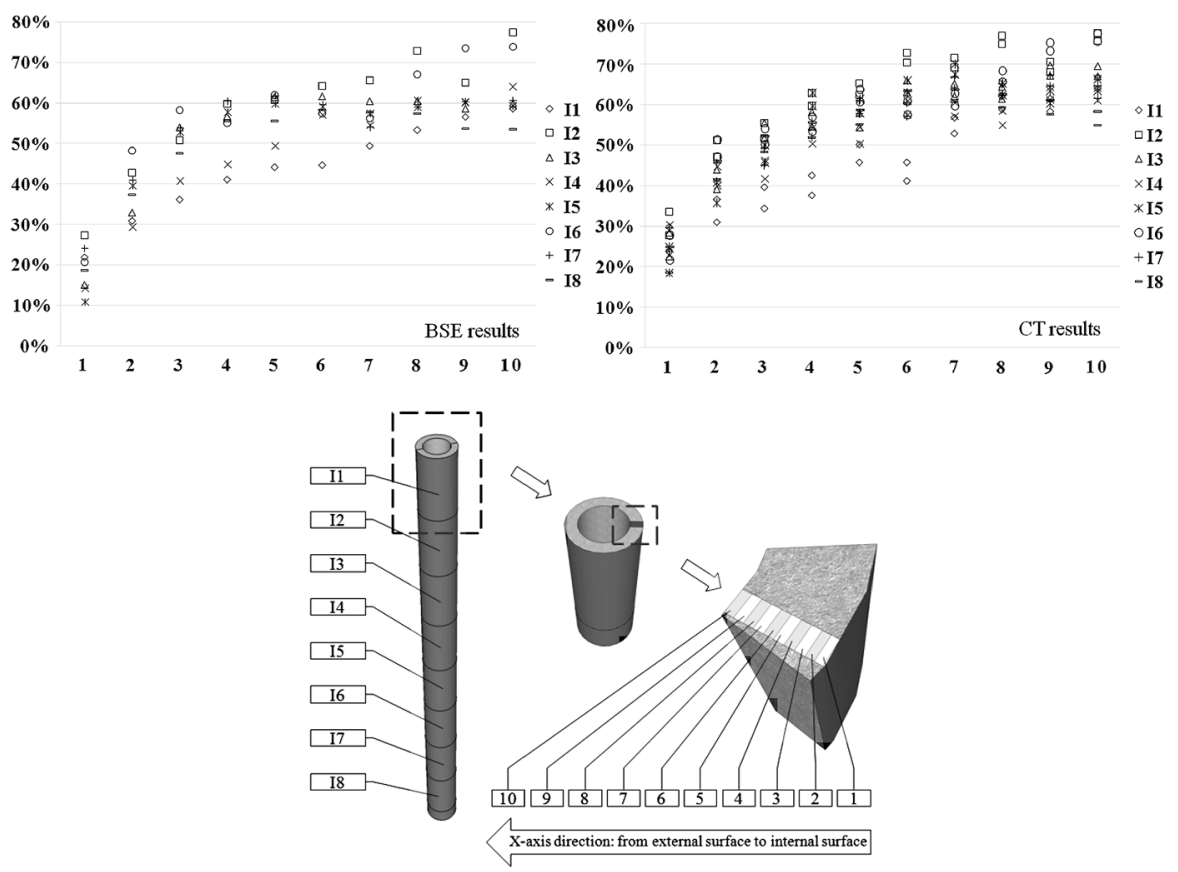

Fig. 6 Porosity results of internode specimens from BSE and CT results comparison by groups 

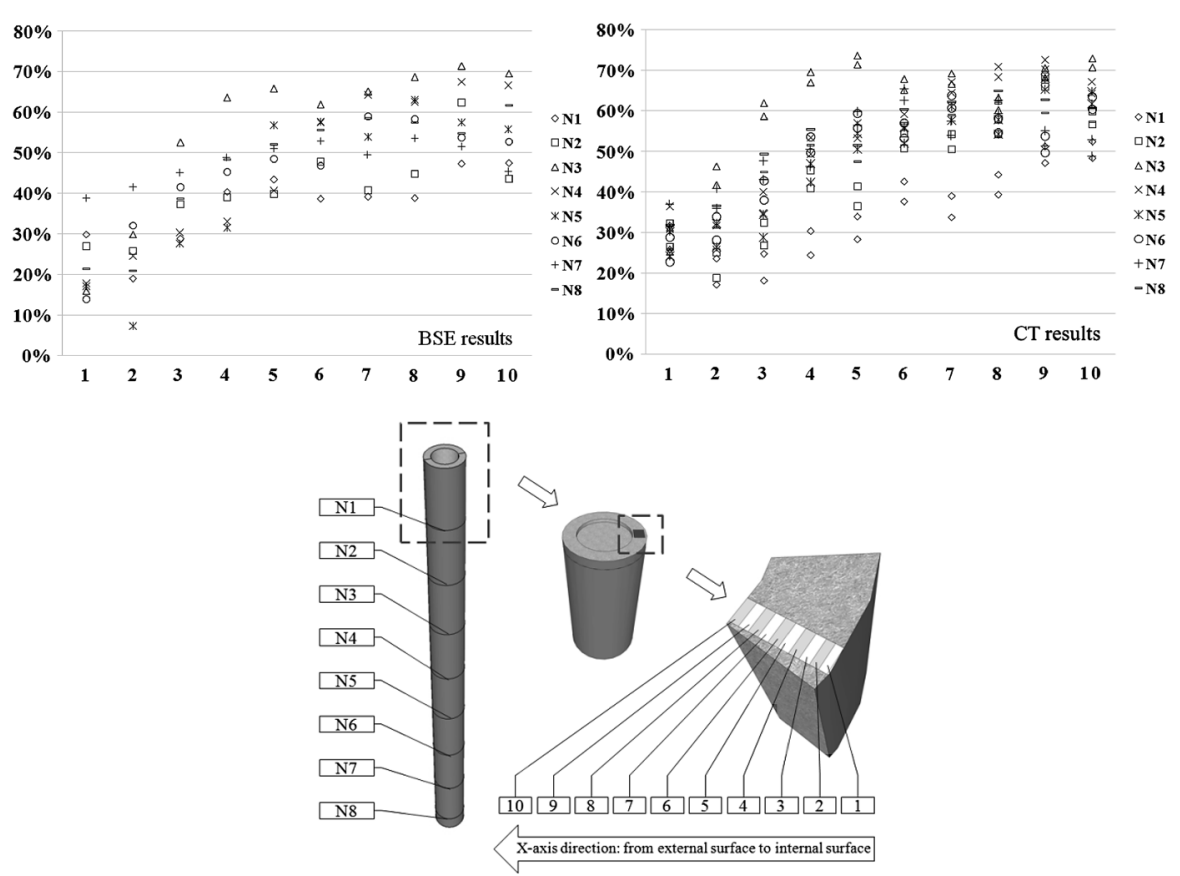

Fig. 7 Porosity results of node specimens from BSE and CT results comparison by groups

horizontal axis represents the sequence number of the average values. The vertical axis represents the porosity values. Every figure has eight data series. In BSE side, each series includes a single data line. In CT side, each series includes a maximum porosity line and a minimum porosity line.

The porosity of both internode and node specimens increases from external side to internal side of bamboo culm. The CT scanning results show similar trend to BSE results. The lowest porosity values of both internode and node specimens are mainly from the smallest external diameter of bamboo culms. The N5 specimen needs to be noticed. In BSE result, the N5 specimen shows the lowest porosity at portion two, but it did not show similar trend in CT results. The reason is that the growing direction of vascular bundle tissue becomes irregular in the node specimen. The BSE results are based on the cross section image. If porous vascular bundle tissue grows under the cross section, the pore will not be included in the cross section image. But this tissue could be detected in the three-dimensional CT measurement line. For internode specimens, the difference among I4, I5, I7 and I8 is not considerable. Both I 2 and I6 show high porosity. For node parts, N3 has the highest porosity. The fluctuation of nodes specimens is stronger than the internodes specimens.

Table 2 indicates that external diameter of the bamboo culm is decreasing with the height. From I1 or N1 to I8 or N8, the height of cutting position is decreasing. Figures 6 and 7 also demonstrate the relationship between the porosity and the height of cutting position. The porosity of the specimen from highest cutting 

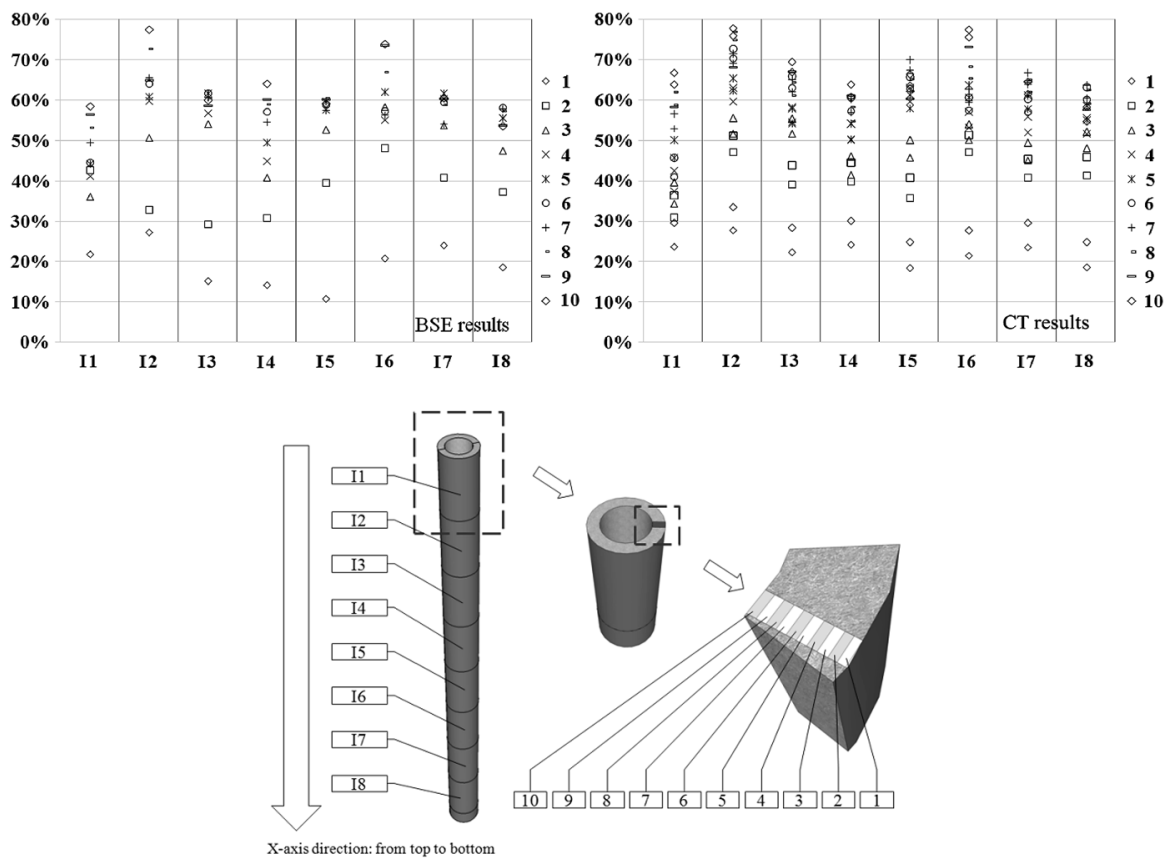

Fig. 8 Porosity results of internode portions from BSE and CT results comparison by portions
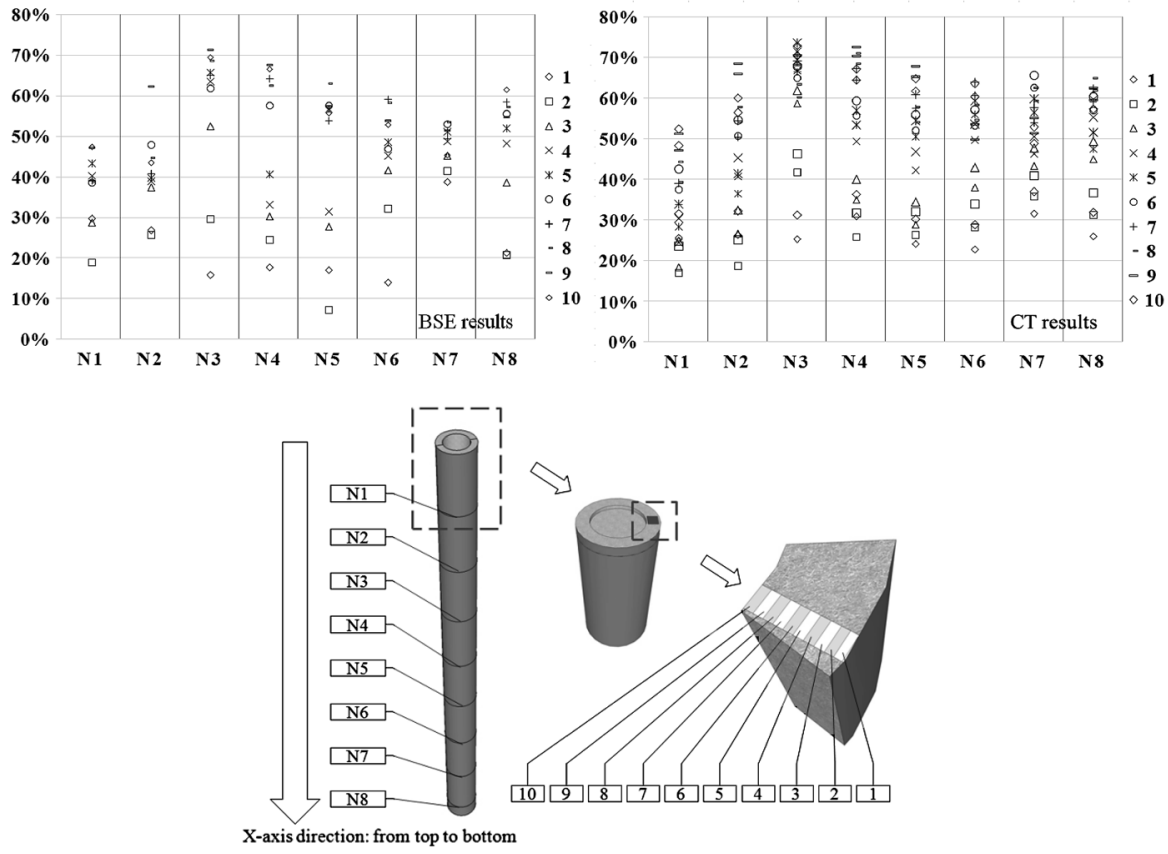

Fig. 9 Porosity results of nodes portions from BSE and CT results comparison by portions 
position is lowest at both internode and node part. The highest porosity is not found at the lowest cutting position. The porosity from I2 and N3 showed the highest porosity at internode part and node part, respectively.

Figures 6 and 7 compare the difference among the specimens with different external diameter of bamboo culms. Each series represents a specimen. Figures 8 and 9 are utilised to compare the difference among ten portions. Each series represents a portion number. The porosity is increasing from portion 1 to portion 10 .

In portions comparison, the porosity fluctuation of internode specimens is similar to the Sine or Cosine curve. The porosity fluctuation of node specimens demonstrated larger fluctuation in each single line than internodes specimens. The similarity between the BSE and CT results is lower in the nodes specimens than the internode specimens. The aforementioned PPMCC comparison has proved this fact.

The porosity is increased with the portion number, namely the distance to the external side of the bamboo culm wall. This trend is more significant than the trend of the height and the porosity. The porosity of BSE results is lower than the CT results at portion 1 and portion 2 from both internode and node specimens, especially for I3 and I5 specimens.

\section{Conclusion}

Computed Tomography (CT) and backscattered electron (BSE) imaging are the two effective technologies to measure the actual morphological porosity distribution from external side to the internal side of the bamboo culm wall. The CT scanning results show similar trend with BSE results. The correlation relationship between BSE and CT results could approach moderate correlation level to strong correlation level. The average porosity of internode specimens is from 43.9 to $58.8 \%$ by BSE measurement and from 44.9 to $63.4 \%$ by CT measurement. The average porosity of node specimens is from 37.4 to $56.6 \%$ by using BSE measurement and from 32.1 to $62.2 \%$ by CT measurement. Macro statistics, typical porosity results from 400 sampling points and 10 portions average porosity results indicated that the BSE porosity results are lower than the CT results. The reason is that the BSE results are based on the cross section image. If the pores are under the cross section, it will not be included in the cross section image, but these pores could be calculated in the three-dimensional CT measurement line. The porosity fluctuation of node specimens demonstrated larger fluctuation in each single line than internodes specimens. The similarity between the BSE and CT results is lower in the nodes specimens than the internode specimens. The porosity is increased with the portion number, namely the distance to the external side of the bamboo culm wall.

The limitation of this study includes four aspects. First, BSE porosity measurement based on the image processing method, the accuracy is influenced by the image quality. Second, BSE porosity measurement is two dimensional. Third, CT measurement depends on the accuracy of the skeletal cell wall density. This density has relatively wide range which leads to relatively wide porosity range. Finally, compromises need to be made between the time and the number of the measurement specimens and the area of the measurement. 
Nevertheless, this study has provided large number of porosity data from eight bamboo culms with different external diameters and culm wall thickness. Both internodes and node position were included in this study. The porosity variation in the radial direction of Moso bamboo culm wall has been illustrated. The porosity results are expected to be utilised in the heat and moisture transfer simulation studies in the future.

Open Access This article is distributed under the terms of the Creative Commons Attribution 4.0 International License (http://creativecommons.org/licenses/by/4.0/), which permits unrestricted use, distribution, and reproduction in any medium, provided you give appropriate credit to the original author(s) and the source, provide a link to the Creative Commons license, and indicate if changes were made.

\section{References}

Almeida G, Hernández RE (2006) Changes in physical properties of tropical and temperate hardwoods below and above the fiber saturation point. Wood Sci Technol 40(7):599-613

Benson-Cooper DM (1982) Computed tomographic scanning for the detection of defects within logs. New Zealand Forest Service, Rotorua

Chinga-Carrasco G (2002) Microscopy and computerized image analysis of wood pulp fibres multi-scale structures. Microscopy: science, applications and education. Formatex, Badajoz, pp 2182-2189

Cook RA, Hover KC (1993) Mercury porosimetry of cement-based materials and associated correction factors. Constr Build Mater 7(4):231-240

Dancey C, Reidy J (2004) Statistics without maths for psychology: using SPSS for windows. Prentice Hall, London

Derome D, Zillig W, Carmeliet J (2012) Variation of measured cross-sectional cell dimensions and calculated water vapor permeability across a single growth ring of spruce wood. Wood Sci Technol 46(5):827-840

Ding W-D, Koubaa A, Chaala A, Belem T, Krause C (2008) Relationship between wood porosity, wood density and methyl methacrylate impregnation rate. Wood Mater Sci Eng 3(1-2):62-70

Giesche H (2006) Mercury porosimetry: a general (practical) overview. Part Part Syst Charact 23(1):9-19

Hass P, Wittel FK, Mcdonald SA, Marone F, Stampanoni M, Herrmann HJ, Niemz P (2010) Pore space analysis of beech wood: the vessel network. Holzforschung 64(5):639-644

Hill CA, Papadopoulos AN (2001) A review of methods used to determine the size of the cell wall microvoids of wood. J Inst Wood Sci 15(6; ISSU 90):337-345

Huang P, Chang W-S, Ansell M, Chew YMJ, Shea A (2015) Density distribution profile for internodes and nodes of Phyllostachys edulis (Moso bamboo) by computed tomography scanning. Constr Build Mater 93:197-204

Iassonov P, Gebrenegus T, Tuller M (2009) Segmentation of X-ray computed tomography images of porous materials: a crucial step for characterization and quantitative analysis of pore structures. Water Resour Res 45(9):1-12

Isagi Y, Kawahara T, Kamo K, Ito H (1997) Net production and carbon cycling in a bamboo phyllostachys pubescens stand. Plant Ecol 130(1):41-52

Kellogg R, Wangaard F (1969) Variation in the cell-wall density of wood. Wood Fiber Sci 1:180-204

Pan S, Kudo M (2011) Segmentation of pores in wood microscopic images based on mathematical morphology with a variable structuring element. Comput Electron Agric 75(2):250-260

Paudel S, Lobovikov M (2003) Bamboo housing: market potential for low-income groups. J Bamboo Rattan 2(4):381-396

Roels S, Elsen J, Carmeliet J, Hens H (2001) Characterisation of pore structure by combining mercury porosimetry and micrography. Mater Struct 34(2):76-82

Siau J (1984) Wood structure and chemical composition. Transport processes in wood. Springer, Berlin Heidelberg 
Solomonov I, Talmi-Frank D, Milstein Y, Addadi S, Aloshin A, Sagi I (2014) Introduction of correlative light and airsemtm microscopy imaging for tissue research under ambient conditions. Sci Rep 4:5987

Stamm AJ (1929) Density of wood substance, adsorption by wood, and permeability of wood. J Phys Chem 33(3):398-414

Stamm AJ, Hansen LA (1937) The bonding force of cellulosic materials for water (from specific volume and thermal data). J Phys Chem 41:1007-1016

Stone J (1964) The porous structure of wood and fibres. Pulp Pap Mag Can 1:T3

Taud H, Martinez-Angeles R, Parrot JF, Hernandez-Escobedo L (2005) Porosity estimation method by X-ray computed tomography. J Pet Sci Eng 47(3-4):209-217

Van Der Lugt P, Van Den Dobbelsteen AAJF, Janssen JJA (2006) An environmental, economic and practical assessment of bamboo as a building material for supporting structures. Constr Build Mater 20(9):648-656

Wu X, Ma H, Chen X, Li Z, Li J (2013) Thermal conductivity and microstructure properties of porous sic ceramic derived from silicon carbide powder. New J Glass Ceram 3(15):43-47

Zauer M, Pfriem A, Wagenführ A (2013) Toward improved understanding of the cell-wall density and porosity of wood determined by gas pycnometry. Wood Sci Technol 47(6):1197-1211

Zauer M, Kretzschmar J, Großmann L, Pfriem A, Wagenführ A (2014) Analysis of the pore-size distribution and fiber saturation point of native and thermally modified wood using differential scanning calorimetry. Wood Sci Technol 48(1):177-193 